\title{
تطوير المواد لمهارة الكلام على أساس النظية البنيوية لتلاميذ المرحلة المتوسطة و المرحلة \\ المتقدمة بمعهد الروضة العلمية كرتوسونو جاوى الشرقية
}

Usfiyatur Rusuly ${ }^{*}$

Email: usfierusuly@yahoo.co.id

\begin{abstract}
ABSTRAK
Ma'had Ar Roudlotul Ilmiyah Kertosono mempunyai kegiatan untuk siswa-siswi yaitu muhadatsah al lughoh. Masing-masing wajib mengikutinya, dalam kegiatan ini tidak ada buku pegangan khusus dalam pembelajaran muhadatsah al lughoh. Penelitian ini akan diadakan di Ma'had Ar roudlotul Ilmiyah untuk tingkatan menengah dan tingkatan atas, peneliti mengembangkan buku ajar keterampilan berbicara berdasarkan teori bunyawiyah yaitu dengan menggunakan hiwar/percakapan, latihan-latihan, dan meningkatkan ketertarikan mereka terhadap Bahasa Arab.

Pada pembahasan ini, akan dibahas cara penyusunan materi ajar bahasa Arab untuk tingkatan menengah dan tingkatan atas yaitu dari penentuan maharah (keterampilan bahasa yang akan digunakan), batasan-batasan isi, dan pelaksanaan penyusunan materi ajar hingga menjadi produk akhir yang dapat digunakan dalam proses belajar mengajar dengan menggunakan metode Research and Depelopment (R \& D).
\end{abstract}

Kata Kunci: Pengembangan buku ajar, Keterampilan berbicara, Teori Bunyawiyah, Reseach and Depelopment (R \& D).

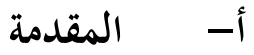

الكلام في اللغة الثانية من المهارات الأساسية التي تمثل غاية من غايات الدراسة اللغوية. وإن

كان هو نفسه وسيلة للاتصال مع الآخرين. (رشدي أحمد طعيمة، 1919: . 1 1) الكلام هو وسيلة

التعبير الإنساني عن الأفكار وخوالج النفس عن طريق جهاز النطق لتوصيلها من مرسل إلى متلقّ في

بحمع ما وفقا لنواميس اللغة التى يتفاهم بها أبناء ذلك المجتمع، وما احتاج الإنسان إلى تسجيل هذه

الرسائل المنطوقة للرجوع إليها عند الحاجة أو لنقلها إلى مكان بعيد حيث يوجد المتلقى كانت الرموز

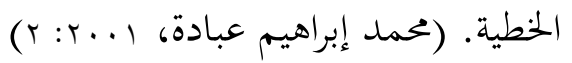

* طالبة في الدراسة العليا بجامعة مولانا مالك إبراهيم الإسلامية الحكومية مالانق 
أن الكلام هو قدرة الإنسان على أن يتحدث بطلاقة وضوح، وأن يكتب بدقة وحسن عرض، وأن يعبر عما في نفسه من موضوعات تلقى عليه، أو عما يحسن بالحاجة إلى الحديث عنه

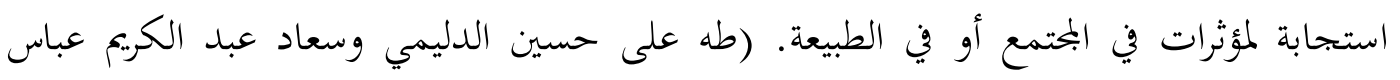

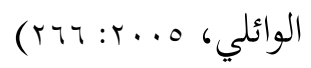

في معهد الروضة العلمية كرتوسونو هناك أنشطة التلاميذ بعد صلاة الصبح يعني محادثة اللغة. وكل التلاميذ يجب أن يشتركوا في تلك الأنشطة. في هذه الأنشطة هناك ثلاث مراحل، المرحلة الابتدائية، المرحلة المتوسطة، والمرحلة المتقدمة. و في هذه الأنشطة ليس هناك كتاب الخاص لتعليم محادثة اللغة. و تريد الباحثة أن تصمم كتاب محادثة اللغة لتلاميذ المرحلة المتوسطة، والمرحلة المتقدمة ليساعد المعلم والتلاميذ في عملية التعليم و التعلّم. ويشجع التلاميذ للاتصال باللغة العربية بينهم. واستعملت الباحثة النظرية البنيوية كي يمارس التلاميذ التكرار، والتدريبات لأن هذا المواد تكثر في التكرار الحوار والتدريبات.

\section{ب- - ب المواد التعليمية}

المواد التعليمية هي الختوى التعليمي الذى يرغب في تعليمه للتلاميذ بغرض تحقيق أهداف تعليمية معرفية أو مهارية أو وجدانية. وهي المضمون الذى يتعلمه التلاميذ في علم ما. (عبد الرمن

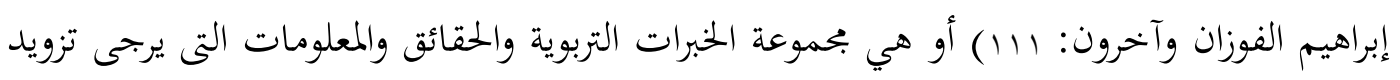
التلاميذ بها، والاتحاهات والقيم التي يراد إكتساهما إياهم، بمدف تحقيق النمو الشامل المتكامل لهم في ضوء الأهداف المقررة في المنهج.

وفي تعيين عناصر المواد التعليمية لابد من الاهتمام بنوع المواد، و هي من نوع الحقائق أو المفاهيم أو المبادئ أو الإجراءات. ومعرفة تلك العوامل الأربعة سوف تنفع المدرس في القيام بالعملية التعليمية في الفصل، لأن كلا منها تحتاج إلى استراتيجية والوسائل المختلفة. أضف إلى ذلك لابد من أن يهتم المبادئ المستخدمة لتعيين عناصر المواد التعليمية التي يشمل على وسع مضمونها

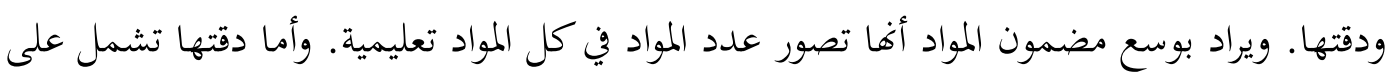
دقة المفاهيم (concepts) التي تتضمن فيه، والتي لابد للتلاميذ تعلمها واستيعاها. والكفاية 
أي مناسبة شمولية المواد مهم لمعرفة كثرتا أو قلتها أو مناسبتها للحصول على الكفاءة (adequacy) (الأساسية.. M Joko Susilo, 2007: 140-141) الترتيب في تقديم المواد التعليمية (sequencing) مهم لتعيين الترتيب في تعليمه وتعلمها، بدونه يصعب في العملية التعليمية لاسيما إذا كانت المواد لما علاقة شرطية (prerequisite). وبدئ ترتيب المواد التعليمية تعيين شموليتها ودقتها بمدخلين أساسيين وهما المدخل الإجرائي ( procedural (approach الخطوات مرتبا حسب الخطوات في تنفيذ أو عمل ما. وأما ترتيبها بالمدخل الهرمي يصور الترتيب على شكل التدرج أو تعلم المواد الجمديدة لابد من تعلم المواد قبلها. الترتيب في تصميم المواد نافع لتعيين ترتيب التعلم والتعليم. وبدونه يصعب على المدرس القيام بعملية التعليمية لاسيما إذا كان المواد لما علاقة شرطية أو علاقة هرمية. وثمة ألأسلوب في ترتيب المواد التعليمية منها: ا- - الطريقة الإجرائية (procedural approach) وهو طريقة تطوير المواد التعليمية معتمدا على الخطرات المرتبة في عملية الوظيفة التعليمية ونتهائها.

r- - الطريقة الهرمية (hierarchy approach)، وهو طريقة تطوير المواد التعليمية معتمدا على تدرج في المواد التعليمية. ويستخدم هذه الطريقة في المواد التي لها علاقة شرطية بالمواد أخرى، ومعنى هذا استيعاب المواد الجحديدة يلزم معه استيعاب المواد قبلها. r- الطريقة الدورية (spiral approach)، وهو طريقة تطوير المواد التعليمية معتمدا على الإعادة في المواد ما. وتختلف في دقتها ووسعها. ع- الطريقة الموضوعية (subject approach)، وهو طريقة تطوير المواد التعليمية منطلقا من موضوع معين. هـ - الطريقة الشبكية (webbed approach)، وهو من الطريقة التكاملية ( integrated approach رئيسية، وترسمها الموضوع وعناصرها كشبكة.

وهناك بعض المبادئ العامة يجب مراعاتا في اختيار المواد التعليمية منها (محمد عبد القادر أحمد، 
ا - صحة المواد ويطلب من ذلك حرصا ووعيا من المعلم في اختيار المواد المعروضة. r- مناسبتها لعقول التلاميذ من حيث مستواها، فلا تكون فوق مستواهم فيملون منها، ولا دون

$$
\text { مستواهم فيستهترون بها. }
$$

r- أن يكون المواد مختارة مرتبطة بحياة التلاميذ وبالبيئة يعيشون فيها. ك- - أن تكون المواد مناسبة لوقت الحصة فلا تكون طويلة بحيث لا يستطيع المعلم أن ينتهي منها في الحصة. ولا قصيرة بحيث أن ينتهي منها في وقت قصير مما يتيح للتلاميذ فرصة اللعب،

$$
\text { وضياع الوقت. }
$$

هـ - يجب أن ترتب المواد ترتيبا منطيقيا بحيث يبنى كل جزء على سابقه ويرتبط بلاحقة من غير تكلف.

7- - أن تقسم المواد المقررة إلى وحدات توزع على أشهر السنة. V- - ربط المواد الدرس الجديد بالمواد الدرس القديم أو ربط موضوع الدرس بغيره من موضوعات المواد، أو ربط بما يتصل به من المواد الأخرى.

رأى طعيمة أن اختيار محتوى المواد له معايير لابد من الإهتمام بها، منها (رشدى أحمد

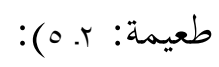

1- معيار الصدق (validity): المختوى صادق عندما يكون واقعيا وأصيلا وصحيحا علميا فضلا

$$
\text { عن تمشيه مع الأهداف الموضوعية. }
$$

r- معيار الأهمية (significance): يعتبر المحتوى مهما عندما يكون ذا قيمة في حياة التلاميذ، مع تغطية الجوانب المختلفة من ميادين المعرفة والقيم والمهارات مهتما بتنمية المهارات العقلية، وأساليب تنظيم المعرفة أو جعلها للمتعلم أو تنمية الابحابية لديه. r- معيار الميول والاهتمامات (interest): يكون المحتوى متمشيا مع اهتمامات التلاميذ عندما يختار على أساس من دراسة هذه الاهتمامات والميول فيعطيها الأولوية دون التصحيح بالطبع بما يعتبر مهما لهم. ـ- - معيار قابلية للتعليم (learn ability): المحتوى قابلا للتعليم عندما يراعى قدرات التلاميذ متمشيا مع الفروق الفردية بينهم مراعيا لمبادئ التدرج في عرض المواد التعليمية. 
○ـ - معيار العالمية (universality): يكون المحتوى جيدا عندما يشمل أنماطا من التعليم لاتعترف بالحدود الجغرافية بين البشر وبقدر ما يعكس المحتوى الصيغة المحلية للمجتمع ينبغي أن يربط الطالب بالعا لم المعاصر من حوله.

تنظيم المحتوى هو ترتيبة بطريقة توفر أحسن الظروف لتحقيق أكبر قدر من أهداف المنهج. فرق الخبراء في طريقة تقديم المعرفة بين المعارف الحقائق والمفاهيم والتعميمات والمبادئ والنظريات. ورأوا ضرورة اتباع المحتوى بتدرج بالطالب عند تعلمه هذه الأشكال المختلفة من المعرفة. وأشار بيرون Byron

$$
\begin{aligned}
& \text { 1 - تحديد تعميمات التي تشير إلى البحاه العام للبرنامج. } \\
& \text { r- تحديد المفاهيم الأساسية التي تشمل عليها التعميمات المذكورة. } \\
& \text { r- اختيار الحقائق التي توضح التعميمات والمفاهيم. } \\
& \text { ع- ـ صوغ المبادئ أو بناء النظريات. }
\end{aligned}
$$

ويتنوع تنظيم محتوى المواد إلى أنواع، منها:

ا - التنظيم المنظقي (Logical Organization)، يقصد بذلك تقديم المحتوى مرتبا في ضوء طبيعة المواد ذاقا، أي مراعاة الترتيب المنظقي للمعلومات والمفاهيم بصرف النظر عن مدى قابلية التلاميذ. في هذا التنيم تراعى مبادئ التدرج من البسيط إلى المعقد، من السهل إلى

$$
\text { الصعب، من القديم إلى الحديث .... وهكذا إلخ. }
$$

r- التنيم السيكولوجي (Psychological Organization)، يقصد به تقديم المحتوى في ضوء حاجات التلاميذ وظروفهم الخاصة وليس في ضوء طبيعة المواد وحدها، ولا يلتزم هذا التنظيم

$$
\text { بالترتيب المنطقي للمواد. }
$$

مازالت المعايير التي اقترحها تايلر (Tayler) لتنظيم المحتوى سائدة بين خبراء إعداد المنهج أو

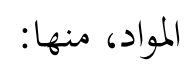


ا- الاستمرارية (continuity): العلاقة الرئيسية بين خبرات المنهج بحيث تؤدى كل خبرة أحداث أثر معين عند الطالب تدعمه الخبرة التالية.

r- التتابع (sequence): بناء الخبرة فوق بعضها البعض. فلا تقدم خبرة لغوية إلا في ضوء ما سبقها، ثم بكيئ هذه الخبرة الطالب بعد ذلك لخبرة التالية. أي أن يكون هناك التسلسل في غرض المهارات وأن تستفيد كل منها مما سبقها ويؤديها لما يلحقها. r- التكامل (integration): العلاقة الأفقية بين الحخبرات حيث يكمل كل منها الآخر. فتدريس

$$
\text { النطق والكام لا ينفصل عن تدريس مهارات الإستماع والقراءة. }
$$

فيرى برونر (Bruner) أنه من اللازم عند تنظيم محتوى المنهج أن يرتكز على المبادئ الأساسية والأفكار والتعليمية حتى تصبح المواد أكثر شمولة في نظر المتعلم، وأكثر سهولة للانتقال من موقف تعليمي لآخر. من خلال ما تقدم نستطيع أن نستخلص الشروط التى يجب مراعاتا عند إعداد الكتاب

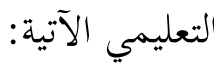

$$
\begin{aligned}
& \text { 1- أن يكون الكتاب مناسبا لمستوى الدارسين فكريا. } \\
& \text { r- أن يراعى مبدأ الفروق الفردية. }
\end{aligned}
$$

r- أن يثير في الدارس التفكير ويساعد على تنمية بما يساعده على اكتساب اللغة الأجنبية (اللغة العربية).

ويعتبر أن تصميم المواد التعليمية الجلديدة في رأي نيفين (Nieveen) إذا توافرت المعايير الآتية: ا - الصدق (Valid)، وهذا المعايير له علاقة بسؤال: هل اعتمد نموذج تطوير على النظرية المعقولة (rational theoretic) r- - يمكن تنفيذه، أي إذا كان يقول على أن ما تطور به يمكن تنفيذه، وتدل الحقيقة على أن ما تطور به قابل للتنفيذ. r- فعال، قدم نيفيم المعيار الآتي: معتمدا على انفعالات الخبرة ويعتبر أن النموذج المصمم فعال، ويأتى هذا النموذج في تطبيقه النتيجة المرجوة. 
ولمعرفة مستوى التناسب من النموذج التعليمى من حيث صدقه يحتاج المصمم الخبير وعامل

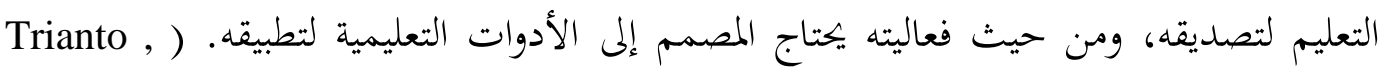
(2007: 8

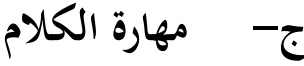

الكلام في أصل اللغة هو الإبانة و الإفصاح عما يجول في خاطر الإنسان من أفكار و مشاعر

بحيث يفهمه الآخرون.( طه علي حسين الدليمي, r...r: ..ب) الكلام في اصطلاح هو فن نقل المعتقدات والمشاعر والإحساسات والمعلومات والمعارف والخبرات والأفكار والأراء من شخص إلى آخر نقلا يقع من المستمع أو المخاطب موقع القبول والفهم والتفاعل والاستجابة. وفي اصطلاح النحاة الجملة المركبة المفيدة. ويقصد (الكلام) نطق الأصوات العربية نطقا سليما بحيث تخرج هذه الأصوات من مخارجها المتعارف عليها لدى علماء اللغة. وتعرف مهارة الكلام بأها كلام باستمرار دون توقف مطلوب ودون تكرار للمفردات بصورة متقاربة مع استخدام الصوت المعير. والطالب عندما أتقن هذه المهارة وأنه يستطيع أن يحقق الهدف الأسمى من اللغة وهو القدرة على الاتصال

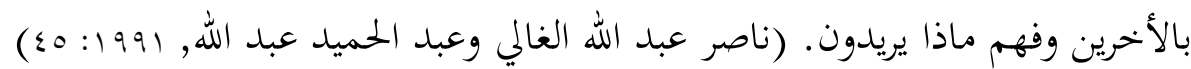
يجب مراعاة الأسس التالية في تعليم مهارة الكلام فلكي نعلم النطق الجيد للناطقين بغير اللغة العربية ينبغي مراعاة الآتية: أن يكون المعلم على كفاءة عالية في هذه المهارة وأن يراعى ما يأتي: '. أن يبدأ بالأصوات المتشاهمة بين اللغتين (لغة الطالب الأولى واللغة العربية). r. . أن يراعي المعلم مبدأ التدرج كأن يبدأ بالألفاظ السهلة المكونة من كلمثين أو ثلاثة أو أكثر.

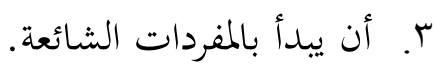
؛. أن يبحث الكلمات التي تحوى حروف المد في بداية الأمر. ○. أن يركز على المهارات الفرعية لمهارة النطق الرئيسية.

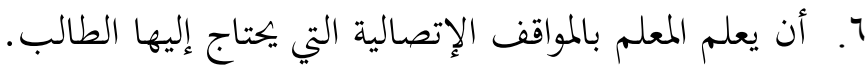
V. كثرة التدريبات المتنوعة المتعددة الأغراض. (ناصر عبد الله الغالي وعبد الحميد عبد الله: \&ه ـ. 
قال رشدي أحمد طعيمة عن تنمية مهارة الكلام، ينتغي تنمية المهارات الآتية في الكلام على

$$
\begin{aligned}
& \text { وفق المستويات التالية(رشدي أحمد طعيمة: VIV-1 V) } \\
& \text { أولا: المستوى الإبتدائى: - أمى }
\end{aligned}
$$

أ)- - مطق الأصوات العربية نطقا صحيحا.

ب)- التمييز عند النطق بين الأصوات المتشاهة مثل (د/ ز/ ط) وكذلك الأصوات المتجاوزة

$$
\text { مثل (ب/ ت ت ث) تمييزا واضحا. }
$$

$$
\text { ج)- التمييز عند النطق بين الحركات الطويلة والحركات القصيرة. }
$$

د)- التمييز صوتيا بين ظواهر المد والشدة، والتفريق بينهما سواء عند النطق بهما أو الإستماع

$$
\text { إليهما. }
$$

هـ) - استخدام الإشارات والإيماءات والحركات استخداما معبرا عما يريد توصيله.

و )- إدراك نوع الانفعال الذي يسود الحديث ويستجيب له في حدود ما تعلمه.

ثانيا: المستوى المتوسط:

أ)- نطق الكلمات المنونة نطقا صحيحا يميز التنوين عن غيره من الظواهر.

ب)- الاستجابة للأسئلة التي توجه إليه استجابة صحيحة مناسبة الهدف من إلقاء السؤال.

ج) - إعادة سرد قصة تلقى عليه.

د) - القدرة على أن يعرض الطالب شفويا وبطريقة صحيحة نصا لحديث ألقي عليه.

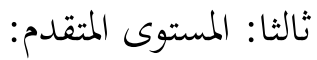

$$
\text { أ)- التعبير عند الحلديث عن احترامه للآخرين. }
$$

ب)- تطويع نغمة صوته حسب الموقف الذي يتحدث فيه. 


$$
\text { ج) - سرد قصة قصيرة من إبداعه. }
$$

د) - استرجاع نص من الذاكرة يحفظه ويلقيه صحيحا، مثل الآيات والأحاديث والأناشيد.

هـ)- التمييز بين أنواع النبر والتنغيم عند الإستماع إليها وتأديتها بكفاءة عند الحديث.

\section{د- النظرية البنيوية}

أقام تشومكسي نظريته اللغوية على أساس أن منظومة اللغة ذات بنية ثنائية. ويقصد بذلك أن الجملة اللغوية لما بنية سطحية ظاهرة هي تلك التي ننطق بها (أي الألفاظ)، وبنية منطقية عميقة، وهي البنية التي تتشكل في مخ صاحب الجملة قبل النطق بها (أي المعاني المرتبة) وعملية الإخراج الصوتي هي عملية تحول هذه البنية العميقة، أي البنية الفكرية، وقد بتسدت ألفاظا، وأصواتا، ونبرا، وتنغيما، وتقديما، وتأخيرا، وإظهارا، وحفظا، وإضمارا. وترى أن الثنائية اللغوية لدى العالمين واضحة. ولكن يرى أن عبد القاهر كان مبدعا في تأكيده أن بنية اللغة إنما تبدأ في الذهن بالوقوف على المعاني وترتيبها، والعلم بمواقعها في النفس، وما يستتبع ذلك من دقة الاختيار والترتيب للألفاظ المنطوقة. وربما كان ذلك هو السبب في أن دي سوسير قد سمى الأفكار والمعاني "البنية العميقة". واستطاع تشومكسي من خلال هذه النظرية أن يثبت وصف أي لغة وقف أصول المدرسة التحليلي الشكلي أمر عسير، أو على الأقل ليس كافيا لتفسير جميع الجمل الصحيحة في لغة ما تفسيرا شاملا: لأن هذا الوصف - في نظره- تعامل مع شكل اللغة وسطحها، وإغفال للجانب

$$
\text { العميق منها. (العصيلي: 9 ؟) }
$$

وعلى هذا الأساس، أصبح علم النحو عند تشومكسي ليس دراسة بحموعة نماذج من الجملة في لغة من اللغات، وإنما هو نظام قائم في عقل إبن اللغة يكتسب ممن الطفولة، ومهمة النظرية اللغوية، أو اللغوي، هي الكشف عن هذا النظام الذي أطلق عليه: الكفاية اللغوية (performance) (competence) لقد رفض تشومكسي الاقتصاد على التحليلي الفونولوجي والمورفولوجي القائم على أساس الشكلي، وعده لونا من التعامل مع السطح اللغة دون عمقها، بل اعتبره أضعف نطقة في التحليلي 
اللغوي. وسعى لإقامة نظريته على أساس أن اللغة عمل عقلي، يتميز به الإنسان عن الحيوان، ومن ثم فإن الهدف الأساس للنظرية اللغوية - في نظره - هو دراسة هذا الجانب العقلي من الإنسان، والكشف عن قدراته اللغوية.

فالنحو عند تشومكسي وأتباعه من النحويين يقوم على أساس من الربط بين البنية العميقة للجملة والأداء السطحي لها، المتثل في الكلام. أما البنية العميقة فتمثل العملية العقلية، أو الناحية الإدراكية التركيبية في اللغة، ودراسة البنية تحتاج إلى فهم العلاقات داخلها، لامن حيث هي وظائف وأشكال على المستوي التركبي، وإنما باعتبارها علاقات تصورية وإدراكية، يؤدي العقل

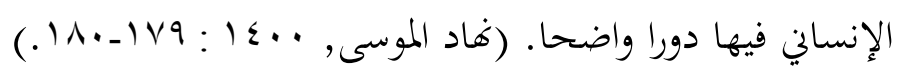

وترتبط المفاهيم البنيانية فيما يختص بتعليم اللغة بمبادئ علم النفس السلوكي ارتباطا وثيقا، فتنظر إلى اللغة على أها نوع من أنواع المثير والاستجابة للمثير، واللغة ضمن هذا الإطار سلوك إنساني. وتقوم المفاهيم البنيانية فيما يختص بتعليم اللغة على النحو التالي: '. تبنى عملية تعليم اللغة على منهجية تكوين عادات كلامية انطلاقا من إثارة المثير ومن الاستجابة التلقائية لهذا المثير.

r. تتم تقوية العادات الكلامية بوساطة تعزيزها وتدعيمها بصورة متواصلة. r. تقتضي الأساليب الأساسية المعتمدة بهدف تنمية الأداء الكلامي للتلميذ الترداد والممارسة وتدعيم العناصر الكلامية وتتابعها في السياق الكلامي.

وأما النجاح في التعلم والتعليم اللغة عند هذه النظرية يتعلق من ثلاثة أوجه: ا ـ المحاكاة، r ( ب. التكرار، ب. والتدريب.

\section{هـ - منهجية البحث والنطوير}

تستخدم الباحثة هنا منهج البحث والتطوير. وهو طريقة البحث الذي يُستخدم لتحصيل المنتج المعين و لتجريب فعالية ذلك المنتج. ( Sugiono, 2010: 307 ولاستطاعة تحصيل المنتج 
المعين يستخدم بحث التحليل الإحتياجات، و لتجريب فعالية ذلك المنتج لوظيفته في البحتمع فيحتاج إلى البحث لتجريب فعالية ذلك المنتج (Sugiono, 2010: 407).

تستخدم الباحثة هذا المنهج لأهما تريد أن تنتج المواد لمهارة الكلام لتعليم اللغة العربية وتقوم

بتجربة فعالية المنتج. وهدف البحث التطويري هو إرادة تقويم التغيير الذي يقع في وقت معين وإنتاج

المنتج على أساس اكتشافات تجربة ميدانية ثم مصادقة عليها و إلى آخرها.

وهذه الأنشطة في البحث والتطوير، ويككن تصويرها في الرسم التالي:

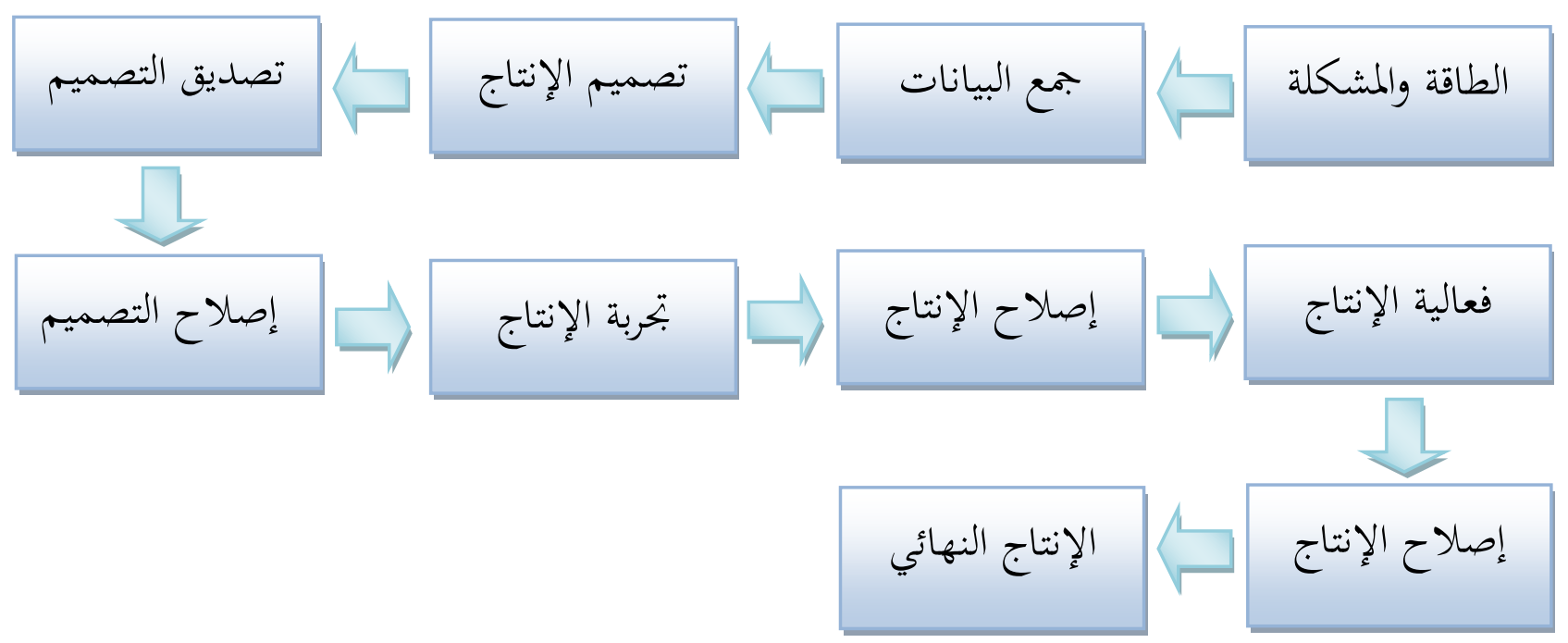

لإجراءات البحث والتطوير فهو الأسلوب الذي قدمه كتاب سوغيونو، وهذا الأسلوب يحتوي

على عشر خطوات ما يلي:

1- الطاقة والمشكلة، البحث يظهر من وجود الطاقة والمشكلة. فالطاقة هي كل شيء إذا

استخدمت فلها نتيجة زائدة. وأما المشكلة فهي اختلاف الشيء المرجو عن الواقع. فالمشكلة

فيمكن أن يحلها البحث التطويري من حيث يوجد الأسلوب الفعال لحل تلك المشكلة

الموجودة. ومشكلة هنا عن المواد التعليمية لمهارة الكلام.

r- جمع البيانات، بعد أن تعرض الطاقة والمشكلة بصفة واقعية وحديثة، فبالتالي جمع البيانات التي

تستخدم كالمواد لتصميم الإنتاج المعين الذي يرجى أن يحل المشكلة الموجودة. وهذا يحتاج إلى

الطريقة التي تتعلق بالمشكلة والأهداف التي يراد بلوغها. 
r- تصميم الإنتاج، وأما الإنتاجات المحصولة باستخدام البحث التطويري فهي متنوعة. و في البحال التربوي، الإنتاجات يرجى أن تطور فاعلية التربية. من الإنتاجات في المحال التربوي هي المنهج الخاص لحاجة التربية الخاصة وطريقة التعليم والوسائل التعليمية والمواد التعليمية وكفاءة

$$
\text { المدرسين وما أشبه ذلك. }
$$

ع- تصديق التصميم، تصديق التصميم هو عملية نشاط لتقويم تصميم الإنتاج. على سبيل المثال، هل طريقة التعليم الجديدة معقولة وستكون أشد فعالا أو لا. ويقال أها معقولة، لأن التصديق في هذه الحالة هو تقويم على أساس الفكر العقلي وليس تطبيقيا. وأما تصديق التصميم فيمكن أداءه بإحضار الخبراء المختبرين في تقويم الإنتاج الجلديد المصمم. يطلب كل خبير أن يقوم ذلك التصميم حتى تعرف مزاياه وعيوبه. ويمكن أداء هذا التصديق بطريقة المناقشة، وقبل ذلك شرحت الباحثة عملية البحث حتى يوجد ذلك التصميم وتشرح كذلك مزاياه.

0- إصلاح التصميم، بعد تصديق التصميم بالمناقشة مع الخبراء وغيرهم، فتعرف عيوب التصميم. وبالتالي، تنقص تلك العيوب بطريقة إصلاحها. وأما الذي يعمل هذا الإصلاح فهو الباحثة

$$
\text { التي تنتج ذلك الإنتاج. }
$$

^- بتربة الإنتاج، في المحال التربوي، فتصميم الإنتاج مثل الطريقة فهي تصلح بحربتها مباشرة بعد تصديقها وإصلاحها. والتجربة في المرحلة الأولى تتم بمحاكاة استخدام طريقة التعليم، وبعد ذلك تصلح بتربتها في المحموعة المحدودة. فإن هذه التجربة تحدف إلى نيل المعلومات عن فعالية طريقة التعليم بالقياس إلى طريقة التعليم القديمة. فتجربة الإنتاج يككن أداءها بطريقة مقارنة الحالة قبل التجربة والحالة بعد بحربة استخدام طريقة التعليم الجديدة، وهذا يسمى بتصميم بتربة القبلي والبعدي. ويمكن أداءها كذلك بطريقة المقارنة بين بحموعة التجربة والمحموعة الضابطة. وهذا قد تم شرحها كاملا في منهج البحث التجريبي. 
V- إصلاح الإنتاج، إذا دلت بتربة الإنتاج في العينة المحدودة السابقة أن طريقة التعليم الجحيدة أكثر فعالية بالنسبة إلى طريقة التعليم القديمة، ويوجد التفاوت بينهما واضحا ومن الممكن كذلك أن يوجد النقص في طريقة التعليم الجحديدة، فهذا يحتاج إلى إصلاحها. ^- فعالية الإنتاج، وفي هذه الحالة، تتم بتربة الإنتاج في البمموعة الواسعة، وفي إجراءها لا بد على الباحثة أن تَتم بعيوبه أو عوائقه لأجل إصلاحه في المرحلة التالية. 9- إصلاح الإنتاج، يعقد إصلاح الإنتاج مرة أخرى، عندما توجد العيوب أو النقائص في بجربة الاستخدام. • اـ الإنتاج النهائي، إذا كان الإنتاج يعتبر فعالا في عديد من التجربات، فيمكن تطبيقه في عملية التعليم الواسع.

تمدف هذه التجربة كما ذكرت الباحثة فيما سبق إلى رفع فاعلية الكتاب التعيليمي، وأيضا إلى الحصول على الاستجابات، والاقتراحات، والتقويمات على صلاحية الكتاب التعليمي في مهارة الكلام، وبالتالي تعرض الباحثة: () تخطيط التجربة، ؟) فاعل التجربة، r) البيانات والمعلومات، ؟) أدوات جمع البيانات، ه) تحليل البيانات.

\section{و - الخلاصة}

اعتمادا على البحث، في تطوير المواد تحتاج إلى المداخل في ترتيب المواد التعليمية، والمعايير في اختيار المواد التعليمية والمحتوى المواد التعليمية، وأسس إعداد المواد التعليمية.

إحدى مراحل الإجراءات في تطوير المواد هي بمنهجيّة التجربة والتطوير (R n D). وعملية تطوير المواد التعليمية مهارة الكالام بإجراء الخطوات التالية: الطاقة والمشكلة، جمع البيانات، تصميم الإنتاج، تصديق التصميم من الخبير تصميم والمحتوى، إصلاح التصميم، بتربة الإنتاج، إصلاح الإنتاج، تجربة الاستخدام ، إصلاح الإنتاج، الإنتاج الجماعي. 
رشدي أحمد طعيمة، تعليم العربية لغير الناطقين بها مناهجه وأساليبه. مصر: جامعة المنصورة، .51919

رشدي أحمد طعيمة، مناهج تلدريس اللغة العربية بالتعليم الأساسي، القاهرة: دار الفكر العربي. طه على حسين الدليمي وسعاد عبد الكريم عباس الوائلي، اللغة العببية مناهجها وطرائق تدريسها، الاردان: دار الشروق للنشر والتوزيع ـ...

طه علي حسين الدليمي، الطرائق العلمية في تلدريس اللغة العربية، عمان ــ الأردن: دار الشروق،

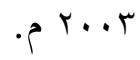
محمد إبراهيم الخطيب، طرائق تعليم اللغة العربية، الرياض: مكتبة التوبة، ب...

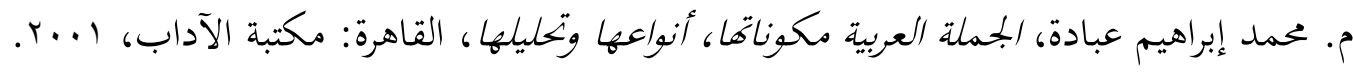
محمد عبد القادر أحمد، طرق تعليم اللغة العربية، القاهرة: مكتبة النهضة المصرية، $19 \vee 9$ م. ناصر عبد الله الغالي وعبد الحميد عبد الله، أسس إعداد الكتب التعليمية لغير الناطقين بالعبية، الرياض: دار الاعتصام، 1991.

Joko Susilo M. KTSP Manejemen Pelaksanaan dan Kesiapan Sekolah Menyongsongnya. Yogyakarta: Pustaka Pelajar, 2007.

Sugiono. Metode Penelitian Pendidikan Pendekatan Kuantitatif, Kualitatif dan $R$ Bandung: Alfabeta, 2010..\&D

Trianto, Model-model Pembelajaran Inovatif Berorientasi Konstruktivistik. Jakarta: Prestasi Pustaka, 2007. 